\title{
Successful Extubation in Preterm Infants
}

\author{
Shabih Manzar ${ }^{1}$ \\ ${ }^{1}$ LSU Health Shreveport
}

January 31, 2022

Successful Extubation in Preterm Infants

To the Editor,

I read with great interest the article by $\mathrm{O}^{\prime}$ Connor et $\mathrm{al}^{1}$ describing factors that lower the likelihood of successful extubation by day 14 in mechanically ventilated neonates with or at risk of developing bronchopulmonary dysplasia (BPD), born at $<30$ week gestational age (GA). These factors were younger GA at birth, and at the time of commencing steroids had higher MAPs and had higher oxygen requirements. They studied 287 neonates and noted that each additional week of GA at birth led to a 1.53 increase in the odds of successful extubation. Higher average fraction of inspired oxygen $\left(\mathrm{FiO}_{2}\right)$ requirements in the preceding $24 \mathrm{~h}$ resulted in a 0.94 decrease in the odds of successful extubation and higher mean airway pressure (MAP) resulted in 0.76 decrease in odds of successful extubation.

I have been using the probability of successful extubation calculator (http://extubation.net/), which incorporates the same factors as described by Connor et al ${ }^{1}$. The calculator was described earlier by Gupta et $\mathrm{al}^{2}$. They incorporated GA, MAP and $\mathrm{FiO}_{2}$ in the calculation, same as Connor et al ${ }^{1}$. The only difference was the inclusion of the respiratory severity score (RSS), which is nothing but a product of $\mathrm{MAP}_{\text {and }} \mathrm{FiO}_{2}$ $\left[\left(\mathrm{RSS}=\right.\right.$ mean airway pressure $\left.(\mathrm{cm} \mathrm{H} 2 \mathrm{O}) \times \mathrm{FiO}_{2}(0.21-1.00)\right]$.

Although, we have a probability score model for successful extubation among preterm infants, as described by Gupta et al ${ }^{2}$, I do agree with Connor et al ${ }^{1}$ that we need to develop prognostic scoring model for intubated preterm infants.

References:

O'Connor K, Hurst C, Llewellyn S, Davies M. Factors associated with successful extubation following the first course of systemic dexamethasone in ventilator-dependent preterm infants with or at risk of developing bronchopulmonary dysplasia [published online ahead of print, 2022 Jan 7]. Pediatr Pulmonol . 2022;10.1002/ppul.25821. doi:10.1002/ppul.25821

Gupta D, Greenberg RG, Sharma A, et al. A predictive model for extubation readiness in extremely preterm infants. J Perinatol . 2019;39(12):1663-1669. doi:10.1038/s41372-019-0475-x

Author:

Shabih Manzar, MD

Louisiana State University Health Sciences Center

Department of Pediatrics

1501 Kings Highway

Shreveport, LA 71103 
Phone: 318-626-1623

Fax: 318-675-6059

Email: shabih.manzar@lsuhs.edu

Author contribution: Dr. Manzar wrote the draft.

Funding and financial support: None

Conflict of interest: None 